International Journal of Applied Research in Mechanical Engineering

July 2013

\title{
MULTI-OBJECTIVE OPTIMIZATION FOR DESIGN OF SINGLE ROW LAYOUT IN FLEXIBLE MANUFACTURING SYSTEM WITH SCHEDULING CONSTRAINT:AN APPROACH OF NONTRADITIONAL OPTIMIZATION TECHNIQUES
}

K. MALLIKARJUNA

BITM, Bellary, k.mallikarjuna@gmail.com

Follow this and additional works at: https://www.interscience.in/ijarme

Part of the Aerospace Engineering Commons, and the Mechanical Engineering Commons

\section{Recommended Citation}

MALLIKARJUNA, K. (2013) "MULTI-OBJECTIVE OPTIMIZATION FOR DESIGN OF SINGLE ROW LAYOUT IN FLEXIBLE MANUFACTURING SYSTEM WITH SCHEDULING CONSTRAINT:AN APPROACH OF NONTRADITIONAL OPTIMIZATION TECHNIQUES," International Journal of Applied Research in Mechanical Engineering: Vol. 3 : Iss. 1 , Article 7.

DOI: $10.47893 /$ IJARME.2013.1110

Available at: https://www.interscience.in/ijarme/vol3/iss1/7

This Article is brought to you for free and open access by the Interscience Journals at Interscience Research Network. It has been accepted for inclusion in International Journal of Applied Research in Mechanical Engineering by an authorized editor of Interscience Research Network. For more information, please contact sritampatnaik@gmail.com. 


\title{
MULTI-OBJECTIVE OPTIMIZATION FOR DESIGN OF SINGLE ROW LAYOUT IN FLEXIBLE MANUFACTURING SYSTEM WITH SCHEDULING CONSTRAINT:AN APPROACH OF NON- TRADITIONAL OPTIMIZATION TECHNIQUES
}

\author{
K.MALLIKARJUNA ${ }^{1}$. V.VEERANNA ${ }^{2}$.K.HEMACHANDRA REDDY ${ }^{3}$ \\ ${ }^{1}$ Associate Professer, BITM, Bellary, \\ ${ }^{2}$ Dean, BITS Kurnool \\ ${ }^{3}($ Registrar, JNTU, Anantapur
}

\begin{abstract}
Single row layout is one of the most usually used layout patterns in industries, particularly in flexible manufacturing systems. Here actual sequencing of machine and arrangement of parts, no doubt, have a great influence on the throughput of the flexible manufacturing system i.e., (F.M.S). This paper discusses the single row layout design in flexible manufacturing system (F.M.S). This paper furnishes the design, development and testing of simulated annealing technique and genetic algorithm to solve the single row layout problem by considering multi-objective i.e., minimizing the make span of jobs on all machines and minimizing the total transportation cost. The various line layout problems are tested for performance of objective function with respect to computational time and number of iterations involved in GA and SA. A necessary code is generated in $\mathrm{C}++$ and the code is run by the IDE tool in which $\mathrm{C}++$ compiler used as plug in. This tool has Eclipse based features which affords the competency to figure, correct, steer, and sort out the tasks that use $\mathrm{C}++$ as a programming language using Intel core $\mathrm{i} 3-380 \mathrm{M}$ processor. The results of the different optimization algorithms (Genetic Algorithm and simulated annealing method) are compared and finally, we observed that GA provide optimum results than SA
\end{abstract}

Keywords- Flexible Manufacturing system;Genetic Algorithm;Makespan;single row layout;Simulated Annealing; Transportation Cost.

\section{INTRODUCTION}

Manufacturing industries are under great pressure caused by the rising cost of energy, materials, labours, capital and intensifying worldwide competition. While these trends will remain for a long time the problem facing manufacturing today runs much deeper. In many cases they stem from the very nature of the manufacturing process itself. In order to overcome that flexible manufacturing system (FMS) is regarded as one of the most efficient methods to use in reducing or eliminating manufacturing problems. FMS is more than a technical solution; it is a business driven solution leading to improved profitability through reducing lead times and inventory levels and improved manufacturing effectiveness through increased operational flexibility, predictability and control. According to Kerney and Trecker:[1]. An FMS is a group of $\mathrm{NC}$ machines tools that can randomly process a group of parts, having automated material handling and central computer control to dynamically balance resource utilization so that the system can adopt automatically to change in parts production, mixtures and levels of output. The objective of FMS is litheness in production without compromising the superiority of products. Flexibility can mean future cost avoidance.

Material handling is important, yet sometimes an overlooked aspect of automation. The main function of an MHS is to supply the right materials at the right locations and at the right time, the cost of material handling has high priority in total cost of production. It means handling cost is equal to $2 / 3$ of the total manufacturing cost Tompkins ja, white ja, bozerya, janchocoJmn (2); The FMS layout involves distributing different resources for achieving maximum efficiency. The layout has an impact on the production time and cost Apple $\mathrm{Jm}$ (3); must be resolved in early stage of the FMS. In practice most commonly used type of FMS layouts Mikell.P.Groover (4) are:

$\begin{array}{ll}\text { 1) } & \text { Line or single row layout } \\ \text { 2) } & \text { Loop layout } \\ 3) & \text { Ladder layout } \\ 4) & \text { Open field layout }\end{array}$

Among the above layouts, this paper focus on single row or line layout design with integrated scheduling using GA and SA.

\section{LITERATURE SURVEY}

In the last decade, FMS layout design with integrate scheduling got more focus because of its importance from both theoretical and practical points of view. Early research was concentrated mainly on the formulation and solution of the problem as the mathematical model, such as interior programing, branch and bound method and dynamic 
programingRuey-Mawchen and Shin-Tang Lo (5); but these approaches can only be useful for small problems. Heuristic methods can solve the small and also combinatorial optimization problems. ShahramAriafar, Napsiah Ismail (6)proposed a new mathematical model for the layout problem in a cellular manufacturing system and a variant of simulated annealing algorithm was developed to solve the problem.R.M.Satishkumar and P.Ashokan(7) introduced an ACO algorithm for the layout design with integrated scheduling by applying priority dispatching rules J.Jerald and R.saravnan(8) presented a paper related to adaptive genetic algorithm applied to scheduling of parts and automated guided vehicles in an FMS. They focused on large variety problem [16 machines and 43 parts] and combined objective function.

\section{PROBLEM DESCRIPTION}

The problem formulation procedure adopted by Hongbo Liu and Ajith Abraham [9] has been used in this research work. We focus on design of line layout in flexible manufacturing system with flexible batch scheduling problem [FBSP] as constraint with the following parameters.

- Jobs $\mathrm{J}=\left\{\mathrm{j}_{1}, \mathrm{j}_{2}, \ldots \mathrm{j}_{\mathrm{n}}\right\} /$ batches $\left\{\mathrm{B}_{1}, \mathrm{~B}_{2}, \ldots \ldots \ldots \ldots \ldots \mathrm{B}_{\mathrm{n}}\right\}$ is a set of $\mathrm{n}$ jobs $/ \mathrm{n}$ batches to be scheduled respectively. Each job $\mathrm{J}_{\mathrm{i}}$ consists of a predetermined sequence of operations. $\mathrm{O}_{\mathrm{i}, \mathrm{j}}$ is the operation $\mathrm{j}$ of $\mathrm{J}_{\mathrm{i}}$.

- Machines $M=\left\{M_{1}, M_{2}, \ldots M_{m}\right\}$ is a set of $m$ machines

- Slots $S=\left\{S 1, S 2, S 3 \ldots \ldots . . S_{m}\right\}$ is a set of $N$ fixed slots

- Flexible FJSP usually is classified into two types as follows:

- Total FJSP $\{$ T-FJSP $\}$; each operation can beprocessed on any machine of $\mathrm{M}$.

- Partial FJSP $\{$ P-FJSP $\}$; each operation canbe processed on one machine of set of $\mathrm{M}$.

- We chose P-FJSP integrated with facility layout problems for our research work.

\section{AMulti-Objective Mathematical Model}

In this section, we introduce the multi-objective function and use it to solve the flexible batch scheduling problems which are integrated with line layout pattern design leads to minimize the make span and to obtain an optimal layout plan for the machines by minimizing the total transportation cost increased in the system.

Notations The notations which are used to develop a mathematical model of the design of line layout are defined and interpreted as follows:

$\begin{array}{lll}\mathrm{i} & - & \text { part type index } \mathrm{i}=1,2,3, \ldots \ldots, \mathrm{n} \\ \mathrm{j} & - & \text { Process index } \mathrm{j}=1,2,3, \ldots \ldots, \mathrm{n}_{\mathrm{i}} \\ \mathrm{k} & - & \text { Machine index } \mathrm{k}=1,2,3, \ldots \ldots, \mathrm{m} \\ \mathrm{n} & - & \text { Number of batches } / \mathrm{job}\end{array}$

\begin{tabular}{|c|c|c|}
\hline $\mathrm{m}$ & - & Number of machines \\
\hline $\mathrm{S}_{\operatorname{maxi}}$ & - & $\begin{array}{l}\text { Make span of system maximum } \\
\text { completion time }\end{array}$ \\
\hline $\mathrm{s}_{\mathrm{n}, \mathrm{m}}$ & - & Make span of system \\
\hline $\mathrm{S}_{\mathrm{i}, \mathrm{j}, \mathrm{k}}$ & - & $\begin{array}{l}\text { Partial make span without } \\
\text { predecessors }\end{array}$ \\
\hline $\mathrm{S}_{\mathrm{i}, \mathrm{j}+1, \mathrm{k}}$ & - & $\begin{array}{l}\text { Enhanced make span with } \\
\text { precedecessors }\end{array}$ \\
\hline $\mathrm{T}_{\mathrm{i}, \mathrm{j}}$ & - & $\begin{array}{l}\text { The duration (processing time) of } \\
\text { operation } j \text { of job } i\end{array}$ \\
\hline $\mathrm{T}_{\mathrm{i}, \mathrm{j}+1}$ & - & The duration of operation $\mathrm{j}=1$ of job $\mathrm{i}$ \\
\hline $\mathrm{M}$ & - & $\begin{array}{l}\text { Total number of machines contained } \\
\text { in the } \\
\text { manufacturing system }\end{array}$ \\
\hline $\mathrm{M}_{\mathrm{i}}$ & - & Machine in slot $\mathrm{n}_{1}$ \\
\hline $\mathrm{M}_{\mathrm{j}}$ & - & Machine in slot $\mathrm{n}_{\mathrm{N}}$ \\
\hline $\mathrm{N}$ & - & Number of slots \\
\hline $\mathrm{MH}_{\mathrm{m} 1, \mathrm{~m} 2}$ & - & $\begin{array}{l}\text { Material handling cost between } \\
\text { machines } \mathrm{m}_{1} \text { and } \mathrm{m}_{2}\left(\mathrm{~m}_{1} \mathrm{~m}_{2}=\right. \\
1,2,3, \ldots \ldots, \mathrm{M})\end{array}$ \\
\hline $\mathrm{RD}_{\mathrm{n} 1, \mathrm{n} 2}$ & - & $\begin{array}{l}\text { Rectangular distance between } \\
\text { machinery locations } n_{1} \text { and } n_{2}\left(n_{1} n_{2}\right. \\
=1,2,3, \ldots \ldots . N)\end{array}$ \\
\hline $\mathrm{MF}_{\mathrm{m} 1, \mathrm{~m} 2}$ & - & $\begin{array}{l}\text { Amount of material flow among } \\
\text { machines } \mathrm{m}_{1} \text { and } \mathrm{m}_{2}\left(\mathrm{~m}_{1} \mathrm{~m}_{2}=\right. \\
1,2,3, \ldots \mathrm{M})\end{array}$ \\
\hline $\mathrm{LOC}_{\mathrm{mi}}$ & - & $\begin{array}{l}\text { Loading cost from loading station to } \\
\text { machines }\end{array}$ \\
\hline $\mathrm{ULOC}_{\mathrm{mi}}$ & - & $\begin{array}{l}\text { Unloading cost from unloading } \\
\text { station to machines }\end{array}$ \\
\hline
\end{tabular}

B Objective Functions

Minimize Make Span, $F\left(S_{\max }\right)$

Minimize, $F\left(S_{\text {max }}\right)=S_{n, m}$

Sub to

$$
\begin{array}{lr}
S_{i, j, k} \leq S_{i, j+1, k}-T_{i, j+1}, \mathrm{j}=1,2,3 \ldots \mathrm{p}-1 \\
S_{i, j, k} \geq 0, \quad \mathrm{j}=1,2,3 \ldots \mathrm{n}
\end{array}
$$

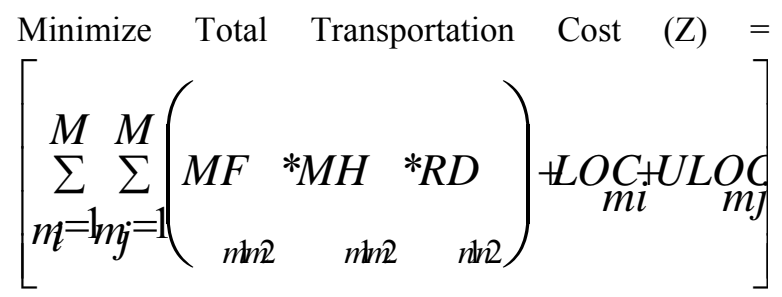

Sub to

$$
\begin{aligned}
& \sum_{m i=1}^{M} X \text { mimj }=1 \text { if machine } \mathrm{m}_{\mathrm{i}} \text { is at assigned } \\
& \text { to slot } \mathrm{N} \\
& =0 \text { otherwise } \\
& \sum_{m j=1}^{M} X \text { mimj }=1 \text { if machine } \mathrm{m}_{\mathrm{j}} \mathrm{is} \text { at assigned } \\
& \text { to slot } \mathrm{N} \\
& =0 \text { otherwise }
\end{aligned}
$$$$
X_{\text {mimj }} \in\{0,1\}, \mathrm{mi}, \mathrm{mj}=1,2, \ldots \ldots \ldots \ldots . \mathrm{N}
$$ 


\section{PROPOSED METHODOLOGY}

The general explanation of the suggested procedures is shared out as follows:

\section{A Genetic Algorithm}

Genetic algorithms are computerized search and optimization algorithms based on the mechanics of natural genetics and natural selection. It is also called a stochastic search procedure for combinational optimization problems. These search technique is commonly used to generate fruitful solutions to optimization and search problems by using the principle of Charles Darwin of "survival of the fittest ", where weak individuals die before reproducing, while stronger ones live longer and bear many offspring and breed children, who often inherit the qualities that enable their parents to survive the reproduced children are in most cases stronger than their parents. The element and mechanism of genetic algorithm are representation, population, evaluation, selection operator and parameter.

\section{B Simulated Annealing Algorithm}

Simulated Annealing (SA) is a meta-heuristic for the overall optimization problem of realistic mathematics, namely finding a good calculation to the total minimum of a given function in large search space.Simulated Annealing was first introduced by Kirkpatrick.S, C.D.Gelett and M.P.Beechi in 1983 and V.Cerny in 1985 to solve optimization problem.It is based on the comparison between finding an optimal solution in solving optimization problems and finding a low energy state in the annealing process of solids. Annealing is a physical process for obtaining a low energy state of a solid in two steps:

- The metal is heated up to the recrystallization point.

- The temperature of the metal is reduced slowly by cooling, allowing it to attain thermal balance at each temperature.

The integral part of an annealing algorithm is its neighborhood generation scheme, on the basis of which different annealing algorithms are developed. The success of these algorithms depends on the quality of the neighborhood generated by the algorithms. In most of the cases generating a neighborhood is mostly problem dependent.

\section{CONFIGURATION OF SINGLE ROW LAYOUT}

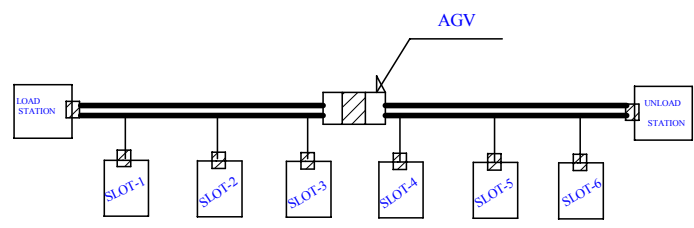

Fig: 1 Single Row Layout Arrangements of FMS for six machines

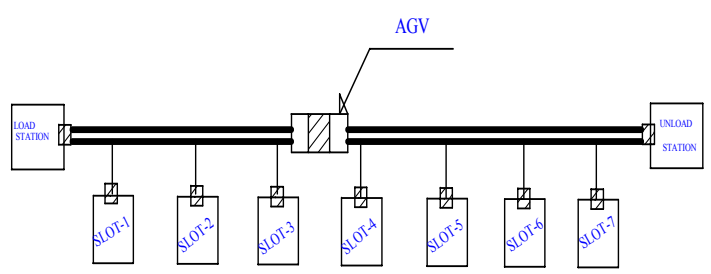

Fig: 2 Single Row Layout Arrangements of FMS for seven machines

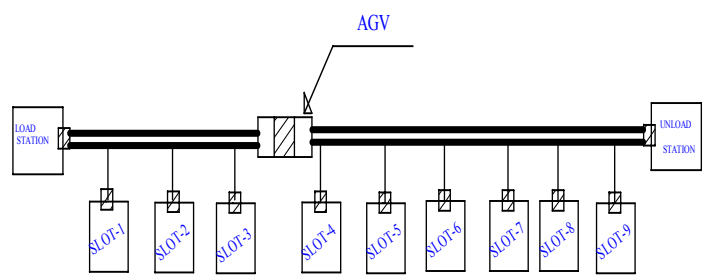

Fig: 3 Single Row Layout Arrangements of FMS for Nine machines

\section{ARITHMETICAL ILLUSTRATION}

An attempt is made to apply the GA and SA algorithms on FMS scheduling to determine the best solution in terms of minimum completion time and obtaining the batch sequence on each machine which facilitates arranging Machines in optimum manner in single row layout to determine non overlapping arrangement of machine owing to that total transportation cost of making necessary mobility of parts is reduced.

4.1The arithmetical illustration of suggested Genetic algorithm for case problem (1) is styled below

1. Choose a feasible chromosomes based on number of operations in case fms scheduling and based on number of machines in single row layout as shown below

a) GA applied to Single row layout

b) Chromosomes 1 and 2 are randomly

selectedchromosome 1: 231564

total transportation cost : $\mathrm{f}(\mathrm{x})=84$

Rschromosome 2 : 463152

total transportation cost : $\mathrm{f}(\mathrm{x})=154 \mathrm{Rs}$

2. Roulette Wheel Selection Procedure

a)Calculate raw fitness for above chromosomes

b) Develop the mating pool

chromosome1: 231564

raw fitness $: \mathrm{F}(\mathrm{x})=1 /(1+\mathrm{f}(\mathrm{x}))$

$=1 /(1+84)=0.01176$

chromosome 2 : 463152

raw fitness : $\mathrm{F}(\mathrm{x})=1 /(1+\mathrm{f}(\mathrm{x}))$

$1 /(1+154)=0.00645$

Finally in mating pool, we got different chromosomes more than what we had previous due to reproduction. Suppose we get 
Multi-Objective Optimization for Design of single row Layout in Flexible manufacturing system with Scheduling Constraint:An Approach

of Non-Traditional Optimization Techniques

chromosome 1:

\begin{tabular}{|l|l|l|l|l|l|}
\hline 3 & 5 & 4 & 6 & 1 & 2 \\
\hline
\end{tabular}

chromosome 2 :

\begin{tabular}{l|l}
2 & 4 \\
\hline
\end{tabular}

c) Cross over Here, we choose single point cross over with 2 point crossing site given below

\begin{tabular}{l|l|l|l|l|l|l|}
\cline { 2 - 7 } chromosome 1: & $\mathbf{3}$ & $\mathbf{5}$ & $\mathbf{4}$ & $\mathbf{6}$ & $\mathbf{1}$ & $\mathbf{2}$ \\
\hline
\end{tabular}

(here, condition is machine numbers should not be repeated while crossing)

\begin{tabular}{|c|c|c|c|c|c|c|}
\hline chromosome 2 : & 2 & 4 & 1 & 5 & 6 & 3 \\
\hline offspring 1 : & 3 & 5 & 1 & 4 & 6 & 2 \\
\hline offspring 2 : & 2 & 4 & 5 & 6 & 1 & 2 \\
\hline
\end{tabular}

offspring 1: $\quad$\begin{tabular}{|l|l|l|l|l|l|}
\hline $\mathbf{3}$ & $\mathbf{5}$ & $\mathbf{1}$ & $\mathbf{4}$ & $\mathbf{6}$ & $\mathbf{2}$ \\
\hline
\end{tabular}

offspring 2: \begin{tabular}{|l|l|l|l|l|l|}
\hline $\mathbf{3}$ & $\mathbf{6}$ & $\mathbf{1}$ & $\mathbf{4}$ & $\mathbf{5}$ & $\mathbf{2}$ \\
\hline
\end{tabular}

4.2 The arithmetical illustration of suggested Simulated Annealing for case problem (3) is styled below

1. Let $\mathrm{TTC}=84 \mathrm{Rs}$

- $\quad$ set $\mathrm{E}(1)=84$ at $\mathrm{T}=100^{\circ} \mathrm{c}$

- best solution so for is $E(1)=84$

2. At next iteration,

If neighboring valve $(\mathrm{TTC})=85 \mathrm{Rs}$

$-\operatorname{set} \mathrm{E}(2)=85$ at $\mathrm{T}=100^{\circ} \mathrm{c}$
- calculate the difference $\mathrm{b} / \mathrm{n}$ two energy

levels i.e

- Now

f . .. Then Calculate the probability of acceptance $(\mathrm{R})=\exp (-\Delta \mathrm{E} / \mathrm{T})$

If $\mathrm{R}<\exp (-\Delta \mathrm{E} / \mathrm{T})$, Then reject the current solution and do not change the best solution

3. Likewise, repeat the iterations until temperature reaches to minimum value and choose the best solution among all iterations

\section{DATA SET DETAILS FOR SINGLE ROW LAYOUT WITH FJSP}

A Production system with the summary and Batch sizes and the layout of FMS .Let there be parts to be processed on machine for various operations. Which requires the processing time and part routing with the operation sequence of parts which steers the parts on various machines given in Table 01 . The inter slot between machines which means the gap between machines measure in units the loading/unloading distance matrix specifies distance from machines to load/unload station, unit material handling cost per unit i.e the carrying cost of parts between machines is unit cost, are depicted in Table 02. The way of part/batch moves over the machines is given in the Table 01 as an input for FMS scheduling, where the objective is to arrive at a layout, which determines non-overlapping optimal sequence of machines such that total cost of making required movements is minimized.

Nomenclature

\begin{tabular}{lc}
\hline Parameter & Description \\
\hline NOM & Number of machines \\
NOB & Number of batches \\
NOP & \\
L/UL & Loading/Unloading station of operations \\
BTC & Batches \\
Slo & Slots \\
CBS & Constant Batch Size \\
VBS & Bable Batch Size \\
\hline
\end{tabular}


Multi-Objective Optimization for Design of single row Layout in Flexible manufacturing system with Scheduling Constraint:An Approach

of Non-Traditional Optimization Techniques

Table1: Data for Flexible batch Shop Scheduling

\begin{tabular}{|c|c|c|c|c|}
\hline $\begin{array}{l}\text { Instance } \\
\text { problem }\end{array}$ & Para & Batch Sizes & Part routing & Part Processing Times \\
\hline 01 & $\begin{array}{l}\text { NOM }-6 \\
\text { NOB }-6 \\
\text { NOP - } 6 \\
\text { L/UL-2 } \\
\text { AGV }-1\end{array}$ & $\begin{array}{lrrrrrr}\text { BTC - B1 } & \text { B2 } & \text { B3 } & \text { B4 } & \text { B5 } & \text { B6 } \\
\text { CBS - 100 } & 100 & 100 & 100 & 100 & 100 \\
\text { VBS - } & 50 & 40 & 60 & 30 & 10 & 25\end{array}$ & 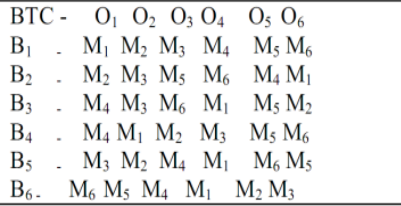 & $\begin{array}{lccccccc}\mathrm{BTC} & -\mathrm{O}_{1} & \mathrm{O}_{2} & \mathrm{O}_{3} & \mathrm{O}_{4} & \mathrm{O}_{5} & \mathrm{O}_{6} \\
\mathrm{~B}_{1}- & 8 & 7 & 14 & 9 & 3 & 4 \\
\mathrm{~B}_{2-} & 10 & 17 & 6 & 13 & 4 & 3 \\
\mathrm{~B}_{3}-18 & 16 & 11 & 12 & 3 & 2 & \\
\mathrm{~B}_{4}-16 & 7 & 11 & 4 & 4 & 13 & \\
\mathrm{~B}_{5}-12 & 15 & 9 & 11 & 3 & 4 & \\
\mathrm{~B}_{6}-8 & 7 & 9 & 6 & 11 & 12 & \end{array}$ \\
\hline 02 & $\begin{array}{l}\text { NOM }-7 \\
\text { NOB }-7 \\
\text { NOP }-7 \\
\text { L/UL }-2 \\
\text { AGV }-1\end{array}$ & $\begin{array}{rrrrrrr}\text { BTC - B1 } & \text { B2 } & \text { B3 } & \text { B4 } & \text { B5 } & \text { B6 } & \text { B7 } \\
\text { CBS - 100 } & 100 & 100 & 100 & 100 & 100 & 100 \\
\text { VBS - } 50 & 40 & 60 & 30 & 10 & 25 & 90\end{array}$ & 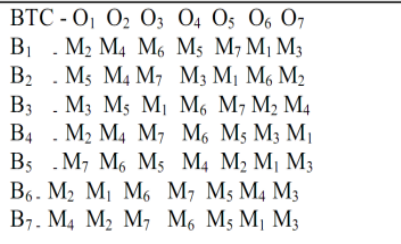 & $\begin{array}{lccccccc}\mathrm{BTC}-\mathrm{O}_{1} & \mathrm{O}_{2} & \mathrm{O}_{3} & \mathrm{O}_{4} & \mathrm{O}_{5} & \mathrm{O}_{6} & \mathrm{O}_{7} \\
\mathrm{~B}_{1}- & 10 & 12 & 11 & 9 & 7 & 7 & 5 \\
\mathrm{~B}_{2}- & 4 & 2 & 4 & 6 & 6 & 5 & 3 \\
\mathrm{~B}_{3}-7 & 6 & 4 & 9 & 10 & 4 & 3 & \\
\mathrm{~B}_{4}-9 & 2 & 9 & 1 & 9 & 4 & 3 & \\
\mathrm{~B}_{5}-4 & 7 & 6 & 7 & 6 & 10 & 6 & \\
\mathrm{~B}_{6}-9 & 3 & 4 & 3 & 6 & 6 & 6 & \\
\mathrm{~B}_{7}-5 & 4 & 3 & 2 & 7 & 7 & 6 & \end{array}$ \\
\hline 03 & $\begin{array}{l}\text { NOM }-9 \\
\text { NOB }-9 \\
\text { NOP }-9 \\
\text { L/UL }-2 \\
\text { AGV }-1\end{array}$ & $\begin{array}{lllllllll}\text { BTC - B1 } & \text { B2 } & \text { B3 } & \text { B4 } & \text { B5 } & \text { B6 } & \text { B7 } & \text { B8 } \\
\text { B9 } & & & & & & & \\
\text { CBS - } 100 & 100 & 100 & 100 & 100 & 100 & 100 & 100 \\
100 & & & & & & & \\
\text { VBS - } 50 & 40 & 60 & 30 & 10 & 25 & 90 & 15 \\
70 & & & & & & & & \end{array}$ & $\begin{array}{llllllllll}\mathrm{BTC} & \mathrm{O}_{1} & \mathrm{O}_{2} & \mathrm{O}_{3} & \mathrm{O}_{4} & \mathrm{O}_{5} & \mathrm{O}_{6} & \mathrm{O}_{7} & \mathrm{O}_{8} & \mathrm{O}_{9} \\
\mathrm{~B}_{1} & -\mathrm{M}_{2} & \mathrm{M}_{4} & \mathrm{M}_{6} & \mathrm{M}_{5} & \mathrm{M}_{7} & \mathrm{M}_{1} & \mathrm{M}_{9} & \mathrm{M}_{3} & \mathrm{M}_{8} \\
\mathrm{~B}_{2} & \mathrm{M}_{5} & \mathrm{M}_{4} & \mathrm{M}_{7} & \mathrm{M}_{3} & \mathrm{M}_{1} & \mathrm{M}_{6} & \mathrm{M}_{8} & \mathrm{M}_{2} & \mathrm{M}_{7} \\
\mathrm{~B}_{3} & \mathrm{M}_{3} & \mathrm{M}_{5} & \mathrm{M}_{1} & \mathrm{M}_{6} & \mathrm{M}_{7} & \mathrm{M}_{2} & \mathrm{M}_{8} & \mathrm{M}_{4} & \mathrm{M}_{9} \\
\mathrm{~B}_{4} & \mathrm{M}_{2} & \mathrm{M}_{4} & \mathrm{M}_{7} & \mathrm{M}_{6} & \mathrm{M}_{5} & \mathrm{M}_{3} & \mathrm{M}_{9} & \mathrm{M}_{8} & \mathrm{M}_{1} \\
\mathrm{~B}_{5} & \mathrm{M}_{8} & \mathrm{M}_{6} & \mathrm{M}_{5} & \mathrm{M}_{4} & \mathrm{M}_{2} & \mathrm{M}_{9} & \mathrm{M}_{7} & \mathrm{M}_{1} & \mathrm{M}_{3} \\
\mathrm{~B}_{6} & \mathrm{M}_{9} & \mathrm{M}_{8} & \mathrm{M}_{6} & \mathrm{M}_{7} & \mathrm{M}_{5} & \mathrm{M}_{4} & \mathrm{M}_{3} & \mathrm{M}_{1} & \mathrm{M}_{2} \\
\mathrm{~B}_{7} & \mathrm{M}_{4} & \mathrm{M}_{2} & \mathrm{M}_{7} & \mathrm{M}_{9} & \mathrm{M}_{5} & \mathrm{M}_{8} & \mathrm{M}_{3} & \mathrm{M}_{6} & \mathrm{M}_{1} \\
\mathrm{~B}_{8} & \mathrm{M}_{1} & \mathrm{M}_{2} & \mathrm{M}_{6} & \mathrm{M}_{7} & \mathrm{M}_{8} & \mathrm{M}_{5} & \mathrm{M}_{3} & \mathrm{M}_{4} & \mathrm{M}_{9} \\
\mathrm{~B}_{9} & \mathrm{M}_{4} & \mathrm{M}_{1} & \mathrm{M}_{8} & \mathrm{M}_{9} & \mathrm{M}_{5} & \mathrm{M}_{7} & \mathrm{M}_{3} & \mathrm{M}_{6} & \mathrm{M}_{2} \\
\end{array}$ & $\begin{array}{lllllllllll}\mathrm{BTC} & \mathrm{O}_{1} & \mathrm{O}_{2} & \mathrm{O}_{3} & \mathrm{O}_{4} & \mathrm{O}_{5} & \mathrm{O}_{6} & \mathrm{O}_{7} & \mathrm{O}_{8} & \mathrm{O}_{9} \\
\mathrm{~B}_{1}- & 11 & 10 & 7 & 19 & 8 & 7 & 9 & 10 & 13 \\
\mathrm{~B}_{2}- & 4 & 12 & 14 & 6 & 2 & 4 & 38 & & \\
\mathrm{~B}_{3}-13 & 16 & 4 & 9 & 10 & 4 & 3 & 7 & 2 \\
\mathrm{~B}_{4}-9 & 12 & 8 & 1 & 9 & 4 & 3 & 9 & 7 \\
\mathrm{~B}_{5}-14 & 7 & 16 & 7 & 6 & 10 & 4 & 5 & 6 \\
\mathrm{~B}_{6}-9 & 13 & 4 & 2 & 6 & 6 & 4 & 7 & 3 \\
\mathrm{~B}_{7}-5 & 14 & 3 & 12 & 17 & 7 & 16 & 5 & 6 \\
\mathrm{~B}_{8}-6 & 4 & 3 & 2 & 7 & 5 & 6 & 5 & 9 \\
\mathrm{~B}_{9}-15 & 14 & 6 & 12 & 7 & 2 & 16 & 2 & 6 \\
\end{array}$ \\
\hline
\end{tabular}

Table2: Data for single row layout

\begin{tabular}{|c|c|c|c|c|}
\hline $\begin{array}{l}\text { Instance } \\
\text { problems }\end{array}$ & Para & Inter slot distance $\mathbf{b} / \mathbf{n}$ machines & $\begin{array}{l}\text { distance from machines to Loading } \\
\text { \&Unloading station }\end{array}$ & Material Handling cost \\
\hline 01 & $\begin{array}{l}\text { NOM -6 } \\
\text { NOB - } 6 \\
\text { NOP - } 6 \\
\text { L/UL- } 2 \\
\text { AGV -1 }\end{array}$ & $\begin{array}{ccccccc}\text { Slo } & \mathrm{S}_{1} & \mathrm{~S}_{2} & \mathrm{~S}_{3} & \mathrm{~S}_{4} & \mathrm{~S}_{5} & \mathrm{~S}_{6} \\
\mathrm{~S}_{1} & 0 & 4 & 6 & 8 & 10 & 12 \\
\mathrm{~S}_{2} & 4 & 0 & 4 & 6 & 8 & 10 \\
\mathrm{~S}_{3} & 6 & 4 & 0 & 4 & 6 & 8 \\
\mathrm{~S}_{4} & 8 & 6 & 4 & 0 & 4 & 6 \\
\mathrm{~S}_{5} & 10 & 8 & 6 & 4 & 0 & 4 \\
\mathrm{~S}_{6} & 12 & 10 & 8 & 6 & 4 & 0 \\
\end{array}$ & $\begin{array}{lrrrrrr}\text { SloS }_{1} & \mathrm{~S}_{2} & \mathrm{~S}_{3} & \mathrm{~S}_{4} & \mathrm{~S}_{5} & \mathrm{~S}_{6} \\
\text { LS } & 3 & 5 & 7 & 9 & 11 & 13 \\
\text { ULS } & 13 & 11 & 9 & 7 & 5 & 3\end{array}$ & $\begin{array}{lllllll}\text { Slo } & \mathrm{S}_{1} & \mathrm{~S}_{2} & \mathrm{~S}_{3} & \mathrm{~S}_{4} & \mathrm{~S}_{5} & \mathrm{~S}_{6} \\
\mathrm{~S}_{1} & 0 & 1 & 1 & 1 & 1 & 1 \\
\mathrm{~S}_{2} & 1 & 0 & 1 & 1 & 1 & 1 \\
\mathrm{~S}_{3} & 1 & 1 & 0 & 1 & 1 & 1 \\
\mathrm{~S}_{4} & 1 & 1 & 1 & 0 & 1 & 1 \\
\mathrm{~S}_{5} & 1 & 1 & 1 & 1 & 0 & 1 \\
\mathrm{~S}_{6} & 1 & 1 & 1 & 1 & 1 & 0 \\
\end{array}$ \\
\hline 02 & $\begin{array}{l}\text { NOM -7 } \\
\text { NOB -7 } \\
\text { NOP -7 } \\
\text { L/UL -2 } \\
\text { AGV -1 }\end{array}$ & 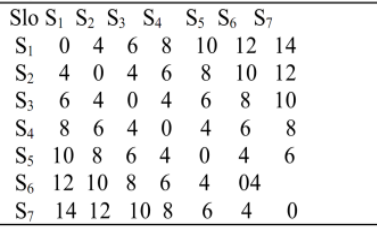 & $\begin{array}{lccccccc}\text { Slo } & \mathrm{S}_{1} & \mathrm{~S}_{2} & \mathrm{~S}_{3} & \mathrm{~S}_{4} & \mathrm{~S}_{5} & \mathrm{~S}_{6} & \mathrm{~S}_{7} \\
\text { LS } & 3 & 5 & 7 & 9 & 11 & 13 & 15 \\
\text { ULS } & 15 & 13 & 11 & 9 & 7 & 5 & 3\end{array}$ & $\begin{array}{clllllll}\text { Slo } & \mathrm{S}_{1} & \mathrm{~S}_{2} & \mathrm{~S}_{3} & \mathrm{~S}_{4} & \mathrm{~S}_{5} & \mathrm{~S}_{6} & \mathrm{~S}_{7} \\
\mathrm{~S}_{1} & 0 & 1 & 1 & 1 & 1 & 1 & 1 \\
\mathrm{~S}_{2} & 1 & 0 & 1 & 1 & 1 & 1 & 1 \\
\mathrm{~S}_{3} & 1 & 1 & 0 & 1 & 1 & 1 & 1 \\
\mathrm{~S}_{4} & 1 & 1 & 1 & 0 & 1 & 1 & 1 \\
\mathrm{~S}_{5} & 1 & 1 & 1 & 1 & 0 & 1 & 1 \\
\mathrm{~S}_{6} & 1 & 1 & 1 & 1 & 1 & 0 & 1 \\
\mathrm{~S}_{7} & 1 & 1 & 1 & 1 & 1 & 1 & 0 \\
\end{array}$ \\
\hline 03 & $\begin{array}{l}\text { NOM -9 } \\
\text { NOB }-9 \\
\text { NOP }-9 \\
\text { L/UL -2 } \\
\text { AGV -1 }\end{array}$ & 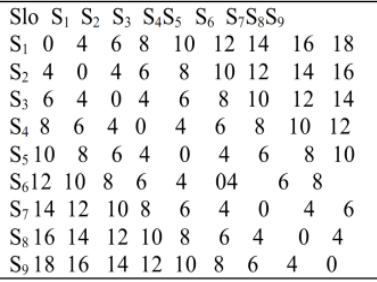 & 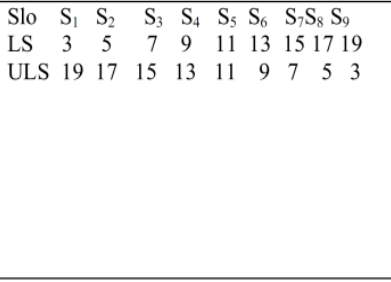 & 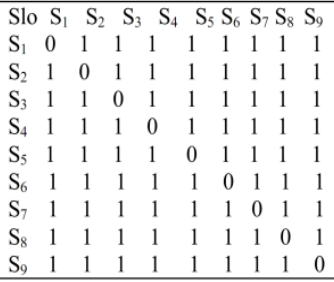 \\
\hline
\end{tabular}

\section{RESULTS \& DISCUSSIONS}

In the present work, the optimal solution for Single Row Layout with integrated scheduling is obtained by using non-traditional optimization techniques such GA and SA.

So far only non-traditional methods are used for solving such kind of problems. In traditional methods to calculate minimum total transportation cost, it is necessary to check (n!)for example :(6!)(1.393140695 $* 10^{17}$ ) sequences in order to find the optimal sequences.

The proposed algorithms based on SA and GA developed and applied on the case study problems taken from the literature P.Udhayakumar, S.Kumanan (2011) given in Table $01 \& 02$;

The essential program is developed in $\mathrm{C}++$ language. The proposed algorithm was coded in $\mathrm{C}++$ and run on an Intel Core ${ }^{\mathrm{TM}} 500 \mathrm{~GB}$ HDD PC. To evaluate the performance of the proposed algorithm, two groups of problems are selected from literature. The summary of the results are obtained for a total of 5runs for each of the problem instances and best set of results are shown in Table 3 to Table 10.

The results include total makespan (MAKSP), the total transportation cost (TTC) and computational time in seconds. 
Multi-Objective Optimization for Design of single row Layout in Flexible manufacturing system with Scheduling Constraint:An Approach of Non-Traditional Optimization Techniques

Table 3: Comparison of arithmetical results of the proposed algorithms for INSTANCE 01 with CBS=100;
\begin{tabular}{|c|c|c|c|c|c|c|}
\hline \multirow{3}{*}{ ITER } & \multicolumn{7}{|c|}{ GA } & \multicolumn{3}{c|}{ SA } \\
\cline { 2 - 7 } & $\begin{array}{c}\text { MAKSP } \\
\text { (mint) }\end{array}$ & $\begin{array}{c}\text { TTC } \\
(\text { Rs })\end{array}$ & $\begin{array}{c}\text { CPU } \\
(\text { mint })\end{array}$ & $\begin{array}{c}\text { MAKSP } \\
\text { (mint) }\end{array}$ & $\begin{array}{c}\text { TTC } \\
\text { (Rs) }\end{array}$ & $\begin{array}{c}\text { CPU } \\
\text { (mint) }\end{array}$ \\
\hline 25 & 8600 & 10400 & 01 & 8400 & 11200 & 0 \\
\hline 50 & 8100 & 10800 & 02 & 8400 & 11000 & 0 \\
\hline 75 & 8100 & 10600 & 08 & 8400 & 11000 & 0 \\
\hline 100 & 8100 & 9800 & 10 & 8400 & 10600 & 0 \\
\hline 125 & 8200 & 10000 & 21 & 8400 & 11000 & 0 \\
\hline 150 & 8000 & 10000 & 29 & 8400 & 10800 & 0 \\
\hline 175 & 8200 & 9800 & 39 & 8300 & 12600 & 0 \\
\hline 200 & 8000 & 9800 & 51 & 8400 & 10800 & 0 \\
\hline
\end{tabular}

Table 4: Comparison of arithmetical results of the proposed algorithms for INSTANCE 02 with CBS=100;

\begin{tabular}{|c|c|c|c|c|c|c|}
\hline \multirow{2}{*}{ ITER } & \multicolumn{3}{|c|}{ GA } & \multicolumn{3}{c|}{ SA } \\
\cline { 2 - 7 } & $\begin{array}{c}\text { MAKSP } \\
(\text { mint })\end{array}$ & $\begin{array}{c}\text { TTC } \\
(\text { Rs })\end{array}$ & $\begin{array}{c}\text { CPU } \\
(\text { mint })\end{array}$ & $\begin{array}{c}\text { MAKSP } \\
(\text { mint })\end{array}$ & $\begin{array}{c}\text { TTC } \\
(\text { Rs })\end{array}$ & $\begin{array}{c}\text { CPU } \\
(\text { mint })\end{array}$ \\
\hline 25 & 7100 & 16400 & 01 & 7200 & 17800 & 0 \\
\hline 50 & 6800 & 10800 & 02 & 7000 & 15400 & 0 \\
\hline 75 & 6800 & 12200 & 09 & 7300 & 15400 & 0 \\
\hline 100 & 6900 & 13200 & 11 & 7200 & 14000 & 0 \\
\hline 125 & 6800 & 16400 & 22 & 7500 & 17200 & 0 \\
\hline 150 & 6800 & 12400 & 32 & 6900 & 14800 & 0 \\
\hline 175 & 6800 & 11800 & 44 & 7100 & 12000 & 0 \\
\hline 200 & 6800 & 12200 & 57 & 6900 & 14800 & 0 \\
\hline
\end{tabular}

Table 5: Comparison of arithmetical results of the proposed algorithms for INSTANCE 03 with CBS=100;

\begin{tabular}{|c|c|c|c|c|c|c|}
\hline \multirow{2}{*}{ ITER } & \multicolumn{3}{|c|}{ GA } & \multicolumn{3}{c|}{ SA } \\
\cline { 2 - 7 } & $\begin{array}{c}\text { MAKSP } \\
(\text { mint })\end{array}$ & $\begin{array}{c}\text { TTC } \\
(\text { Rs })\end{array}$ & $\begin{array}{c}\text { CPU } \\
(\text { mint })\end{array}$ & $\begin{array}{c}\text { MAKSP } \\
(\text { mint })\end{array}$ & $\begin{array}{c}\text { TTC } \\
(\text { Rs })\end{array}$ & $\begin{array}{c}\text { CPU } \\
(\text { mint })\end{array}$ \\
\hline 25 & 11600 & 24400 & 01 & 12200 & 27200 & 0 \\
\hline 50 & 11000 & 24200 & 03 & 11900 & 27800 & 0 \\
\hline 75 & 11600 & 21600 & 10 & 11600 & 22200 & 0 \\
\hline 100 & 11200 & 26800 & 13 & 11200 & 27600 & 0 \\
\hline 125 & 10700 & 24800 & 26 & 11600 & 26200 & 0 \\
\hline 150 & 10900 & 26200 & 36 & 11300 & 29200 & 0 \\
\hline 175 & 10700 & 20800 & 50 & 13000 & 21600 & 0 \\
\hline 200 & 11100 & 20400 & 63 & 11200 & 21600 & 0 \\
\hline
\end{tabular}

Table 6: Comparison of arithmetical results of the proposed algorithms for INSTANCE 01 with VBS;

\begin{tabular}{|c|c|c|c|c|c|c|}
\hline \multirow{2}{*}{ ITER } & \multicolumn{3}{|c|}{ GA } & \multicolumn{3}{c|}{ SA } \\
\cline { 2 - 7 } & $\begin{array}{c}\text { MAKSP } \\
\text { (mint) }\end{array}$ & $\begin{array}{c}\text { TTC } \\
\text { (Rs) }\end{array}$ & $\begin{array}{c}\text { CPU } \\
\text { (mint) }\end{array}$ & $\begin{array}{c}\text { MAKSP } \\
\text { (mint) }\end{array}$ & $\begin{array}{c}\text { TTC } \\
\text { (Rs) }\end{array}$ & $\begin{array}{c}\text { CPU } \\
\text { (mint) }\end{array}$ \\
\hline 25 & 3720 & 4200 & 01 & 3720 & 4210 & 0 \\
\hline 50 & 3730 & 3390 & 02 & 3720 & 4110 & 0 \\
\hline 75 & 3740 & 3530 & 08 & 3720 & 4030 & 0 \\
\hline
\end{tabular}


Multi-Objective Optimization for Design of single row Layout in Flexible manufacturing system with Scheduling Constraint:An Approach of Non-Traditional Optimization Techniques

\begin{tabular}{|l|l|l|l|l|l|l|}
\hline 100 & 3720 & 3430 & 10 & 3720 & 4030 & 0 \\
\hline 125 & 3700 & 3330 & 21 & 3720 & 3930 & 0 \\
\hline 150 & 3730 & 3710 & 29 & 3720 & 3930 & 0 \\
\hline 175 & 3720 & 3430 & 39 & 3720 & 3990 & 0 \\
\hline 200 & 3700 & 3990 & 50 & 3720 & 3990 & 0 \\
\hline
\end{tabular}

Table 7: Comparison of arithmetical results of the proposed algorithms for INSTANCE 02 with VBS;

\begin{tabular}{|c|c|c|c|c|c|c|}
\hline \multirow{2}{*}{ ITER } & \multicolumn{3}{|c|}{ GA } & \multicolumn{3}{|c|}{ SA } \\
\cline { 2 - 7 } & MAKSP & $\begin{array}{c}\text { TTC } \\
\text { (Rs) }\end{array}$ & $\begin{array}{c}\text { CPU } \\
\text { (mint) }\end{array}$ & $\begin{array}{c}\text { MAKSP } \\
\text { (mint) }\end{array}$ & $\begin{array}{c}\text { TTC } \\
\text { (Rs) }\end{array}$ & $\begin{array}{c}\text { CPU } \\
\text { (mint) }\end{array}$ \\
\hline 25 & 3320 & 6380 & 01 & 3440 & 7230 & 0 \\
\hline 50 & 3270 & 5810 & 03 & 3440 & 7190 & 0 \\
\hline 75 & 3725 & 5010 & 09 & 3440 & 7030 & 0 \\
\hline 100 & 3300 & 4320 & 11 & 3295 & 7610 & 0 \\
\hline 125 & 3250 & 4100 & 22 & 3440 & 6570 & 0 \\
\hline 150 & 3375 & 6720 & 31 & 3380 & 7350 & 0 \\
\hline 175 & 3380 & 6430 & 41 & 3400 & 7690 & 0 \\
\hline 200 & 3380 & 5680 & 54 & 3430 & 6650 & 0 \\
\hline
\end{tabular}

Table 8: Comparison of arithmetical results of the proposed algorithms for INSTANCE 03 with VBS

\begin{tabular}{|c|c|c|c|c|c|c|}
\hline \multirow{2}{*}{ ITER } & \multicolumn{3}{|c|}{ GA } & \multicolumn{3}{c|}{ SA } \\
\cline { 2 - 7 } & $\begin{array}{c}\text { MAKSP } \\
(\mathrm{mint})\end{array}$ & $\begin{array}{c}\text { TTC } \\
(\mathrm{Rs})\end{array}$ & $\begin{array}{c}\text { CPU } \\
(\mathrm{mint})\end{array}$ & $\begin{array}{c}\text { MAKSP } \\
(\mathrm{mint})\end{array}$ & $\begin{array}{c}\text { TTC } \\
(\text { Rs })\end{array}$ & $\begin{array}{c}\text { CPU } \\
(\text { mint })\end{array}$ \\
\hline 25 & 7700 & 10570 & 01 & 7920 & 10600 & 0 \\
\hline 50 & 7730 & 7830 & 03 & 7790 & 9720 & 0 \\
\hline 75 & 7650 & 9090 & 10 & 7790 & 9720 & 0 \\
\hline 100 & 7730 & 9440 & 14 & 7790 & 9790 & 0 \\
\hline 125 & 7650 & 8880 & 26 & 7790 & 9720 & 0 \\
\hline 150 & 7650 & 8530 & 36 & 7790 & 9720 & 0 \\
\hline 175 & 7650 & 9530 & 48 & 7790 & 9720 & 0 \\
\hline 200 & 7650 & 8420 & 61 & 7730 & 9680 & 0 \\
\hline
\end{tabular}

Table 9: Comparison of optimum parameters by the proposed evolutionary algorithms (instance 01 for $6 \mathrm{M}-6 \mathrm{~J}-$

$6 \mathrm{O})$

\begin{tabular}{|c|c|c|c|c|}
\hline \multirow{2}{*}{ Para } & \multicolumn{2}{|c|}{ Literature $($ VeerannaV,2004) } & \multicolumn{2}{c|}{ Proposed evolutionary algorithms } \\
\cline { 2 - 5 } & HM & TS & GA & SA \\
\hline MAKSP & 4410 & 5250 & 4150 & 4100 \\
\hline TTC & 8334 & 5300 & 4500 & 5200 \\
\hline
\end{tabular}




\begin{tabular}{|c|c|c|c|c|}
\hline & & & & \\
\hline \multirow{5}{*}{ BWT } & 2160 & 5250 & 1900 & 1850 \\
& 229 & 5380 & 1500 & 1450 \\
& 690 & 3780 & 1050 & 1000 \\
& 2850 & 5850 & 1400 & 1350 \\
& 2790 & 5880 & 450 & 1400 \\
& 700 & 3790 & 1500 & 1450 \\
\hline \multirow{5}{*}{ MWT } & 1637 & 5100 & & \\
& 1347 & 5080 & 1800 & 1750 \\
& 177 & 3930 & 400 & 1300 \\
& 1361 & 4430 & 900 & 350 \\
& 2537 & 5910 & 2800 & 2750 \\
& 1417 & 4830 & 1550 & 1500 \\
\hline
\end{tabular}

The table 3 shows the results of instance 01 for constant batch size (CBS) and is comprehend that, The instance 01 is solved through the proposed algorithm and the results are compared and found that performance of GA and SA for calculating total transportation cost (TTC) and makespan (MAKSP) is varying as number of iterations increases for both algorithms used for $6 \mathrm{M}-6 \mathrm{~B} / \mathrm{J}-6 \mathrm{O}$ (M-machines/Jbatches/jobs-operations) up to 200 generations. By relative analysis, we observed that at $200^{\text {th }}$ iterations solution is optimized for GA and is the best solution when compared with other iterations in GA and for all iterations in SA. Further, the computational time of GA is increases as the iterations increases but the computational time of SA is zero for all iterations.

The table 4 shows the results of instance 02 for constant batch size (CBS) and is figured out that, The instance 02 is solved through the proposed algorithm and the results are compared and found that performance of GA and SA for calculating total transportation cost (TTC) and makespan (MAKSP) is varying as number of iterations increases for both algorithms used for $7 \mathrm{M}-7 \mathrm{~B} / \mathrm{J}-7 \mathrm{O}$ (M-machines/Jbatches/jobs-operations) up to 200 generations. By virtual analysis, we observed that at $50^{\text {th }}$ iteration and $175^{\text {th }}$ iteration solution is optimized for GA and SA respectively. At $50^{\text {th }}$ iteration, GA gives the best solution when compared with other iterations in GA and for all iterations in SA. Further, the computational time of GA is the same up to $50^{\text {th }}$ iteration as in instance 02(table 04), From $75^{\text {th }}$ iteration onward the CPU time increases when compared with the CPU time of instance 02(table 04), but the computational time of SA is the same as table 03 .

The table 5 shows the results of instance 03 for constant batch size (CBS) and is figured out that, The instance 03 is solved through the proposed algorithm and the results are compared and found that performance of GA and SA for calculating total transportation cost (TTC) and makespan (MAKSP) is varying as number of iterations increases for both algorithms used for 9M-9B/J-9O (M-machines/Jbatches/jobs-operations) up to 200 generations. By simulated analysis, we found that at $200^{\text {th }}$ iteration, solution is optimized for GA and SA. At the same iteration, GA gives the best solution when compared with other iterations in GA and for all iterations in SA. Further, the computational time of GA is the same for $25^{\text {th }}$ iteration as in instance 02(table 04), from $50^{\text {th }}$ iteration onward the CPU time increases when compared with the CPU time of instance 02(table 04), but the computational time of SA is the same as table 03 and table 04

Table 6 shows the results of instance 01 for variable batch size(VBS) and is figured out that, The instance 01 is solved through the proposed algorithm and the results are compared and found that performance of algorithms used for $6 \mathrm{M}-6 \mathrm{~B} / \mathrm{J}-6 \mathrm{O}$ (M-machines/Jbatches/jobs-operations) up to 200 generations for calculating total transportation cost (TTC) is varying as number of iterations increases in GA as well as SA and the performance of algorithms are quite different in calculating make span(MAKSP) such that the make span is varying as the number of iterations enhanced in GA whereas in SA the make span do not change due to the scope of SA in searching local optima is very less. By relative analysis, we conclude that at $125^{\text {th }}$ iteration solution is optimized for GA and SA. GA gives the best solution at this iteration when compared with other iterations in GA and for all iterations in SA. Further, the computational time of GA increases as the iterations increases but the computational time of SA is again zero irrespective of batch size for all iterations.

The table 7 shows the results of instance 02 for variable batch size (VBS) and is apparent that, The instance 02 is solved through the proposed algorithm and the results are compared and found that performance of GA for calculating total 
transportation cost (TTC) and make span (MAKSP) is varying as number of iterations increases for both algorithms used for $7 \mathrm{M}-7 \mathrm{~B} / \mathrm{J}-7 \mathrm{O}$ (M-machines/Jbatches/jobs, O-operations) up to 200 generations. By virtual analysis, we conclude that at $125^{\text {th }}$ iteration, solution is optimized for GA and SA. At the same iteration, GA gives the best solution when compared with other iterations in GA and for all iterations in SA. Further, the computational time of GA is the same up to $25^{\text {th }}$ iteration as in the instance 01(table 06), From $50^{\text {th }}$ iteration onward the CPU time is increases when compared with the CPU time of instance 01(table 06), but the computational time of $\mathrm{SA}$ is same as table 06 and it gives results within no time for all iterations. The table 8 shows the results of instance 03 for variable batch size (VBS) and is comprehend that, The instance 03 is solved through the proposed algorithm and the results are compared and found that performance of GA for calculating total transportation cost (TTC) and makespan (MAKSP) is varying as number of iterations increases for both algorithms used for $9 \mathrm{M}-9 \mathrm{~B} / \mathrm{J}-9 \mathrm{O}$ (M-machines/J-batches/jobs-operations) up to 200 generations. By simulated analysis, we finalized that at $50^{\text {th }}$ iteration and $200^{\text {th }}$ iteration, solution is optimized for GA and SA respectively. Finally, GA gives the best solution at $50^{\text {th }}$ iteration when compared with other iterations in GA and for all iterations in SA.Further, the computational time of GA is the same up to $50^{\text {th }}$ iteration as in instance 02 (table 07), From $50^{\text {th }}$ iteration onward the CPU time is increases when compared with the CPU time of instance 02(table 07), but the computational time of $\mathrm{SA}$ is the same as table 06 and table 07. The performance of the proposed evolutionary algorithms such as GA, SA is compared with existing algorithm like TabuSearch, Heuristic methods used in the literature. A comparison of optimum performance parameters by the proposed evolutionary algorithms for instance 01 is shown in Table 9. The results include batch waiting time(BWT), machine waiting time(MWT), total makespan(MAKSP) and total transportation cost(TTC) for single row layout design

\section{GRAPHS}

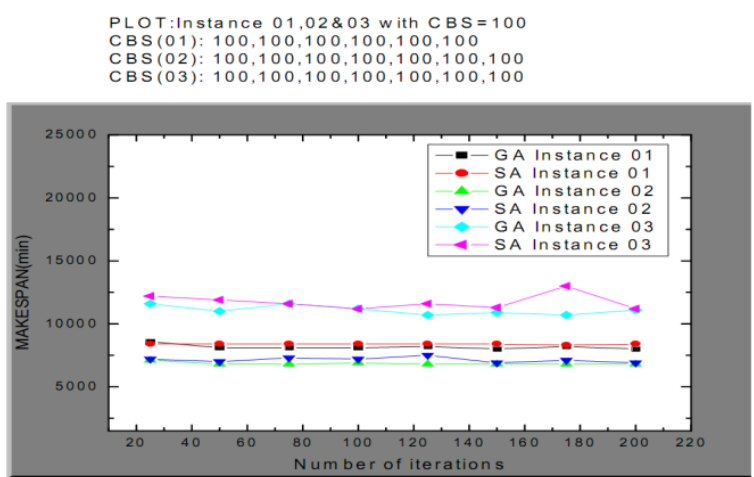

Fig. 4 Comparison of make span for $\mathrm{CBS}=100$ by proposed algorithms(Instance 01,02 and 03)
PLOT:Instance 01,02\&03 with CBS $=100$

CBS(01): $100,100,100,100,100,100$

CBS (02): $100,100,100,100,100,100,100$

CBS(03): $100,100,100,100,100,100,100$

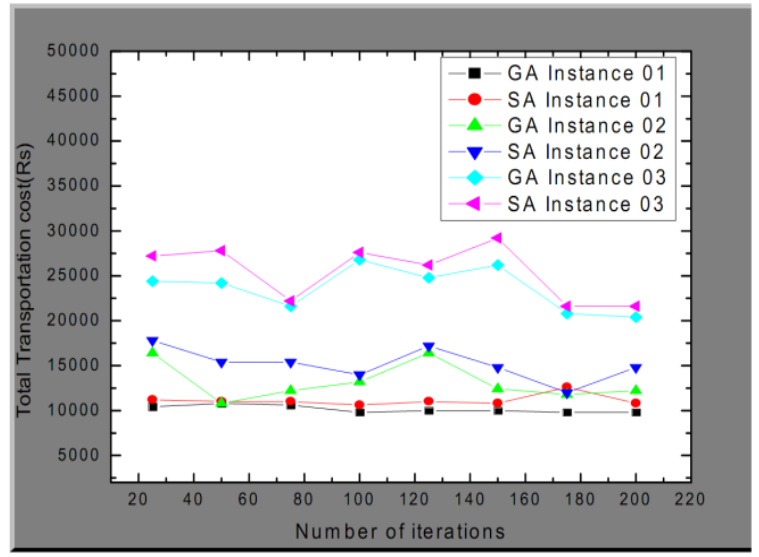

Fig. 5 Comparison of Total Transportation cost (Rs) for CBS by proposed algorithms (Instance 01,02 and 03 )

PLOT:Instance $01,02 \& 03$ with VBS

VBS (01): $50,40,60,30,10,25$

VBS (02): $50,40,60,30,10,25,90$

VBS (03): $50,40,60,30,10,25,90,15,70$

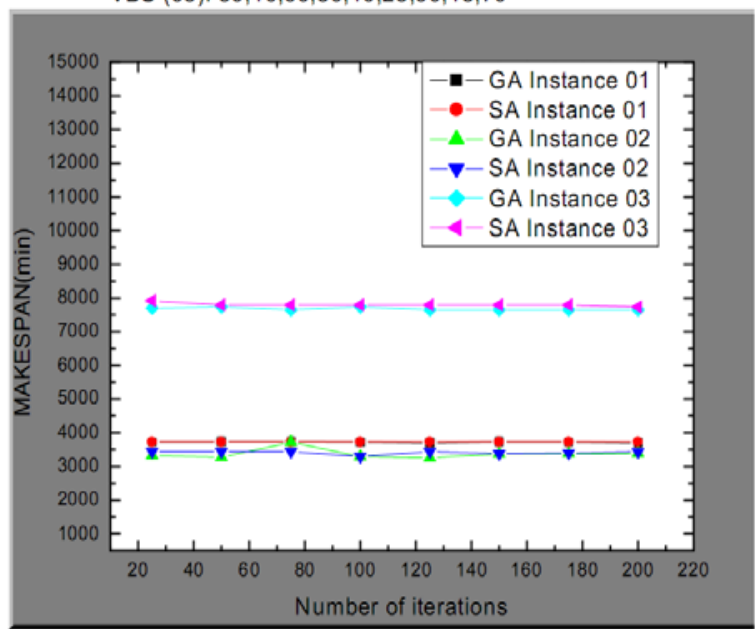

Fig. 6 Comparison of makespan for VBS by proposed algorithms (Instance 01,02 and 03

PLOT:Instance 01,02\&03 with VBS

VBS $(01): 50,40,60,30,10,25$

VBS (02):50,40,60,30,10,25,90

VBS $(03): 50,40,60,30,10,25,90,15,70$

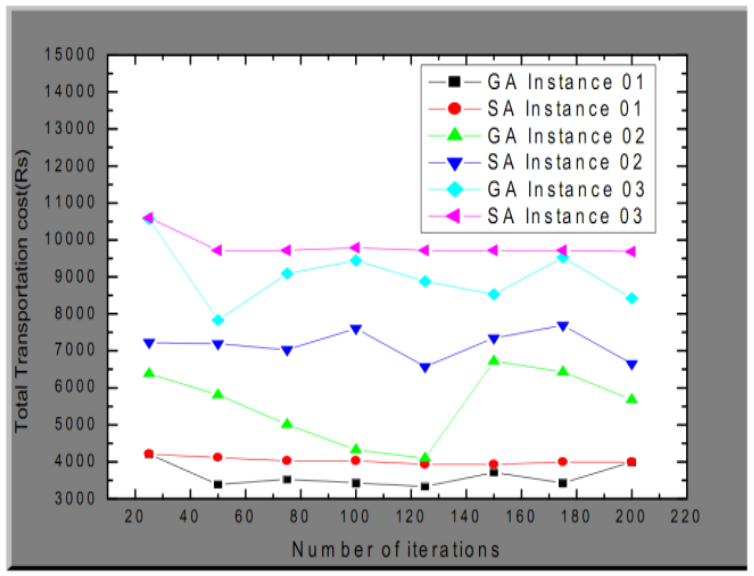

Fig. 7 Comparison of Total Transportation cost (Rs) for VBS by proposed algorithms (Instance 01,02 and 03) 
PLOT:Instance $01,02 \& 03$ with $\mathrm{CBS}=100$ CBS(01): 100,100,100,100,100,100

CBS(02): $100,100,100,100,100,100,100$

CBS(03): $100,100,100,100,100,100,100$

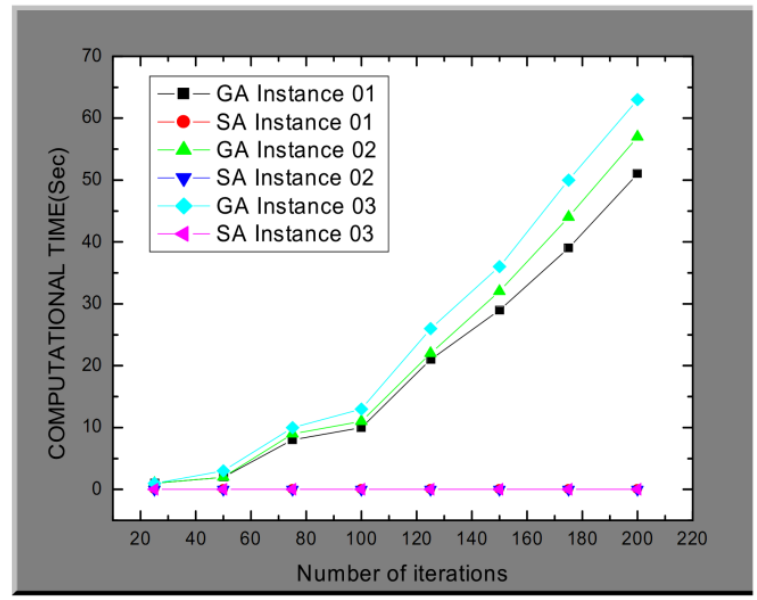

Fig:8 Comparison of ComputationalTime(Sec) for CBS by proposed algorithms(Instance 01,02 and 03 )

PLOT:Instance 01,02\&03 with VBS

VBS (01): $50,40,60,30,10,2$

VBS (02): $50,40,60,30,10,25,90$

VBS (03): $50,40,60,30,10,25,90,15,70$

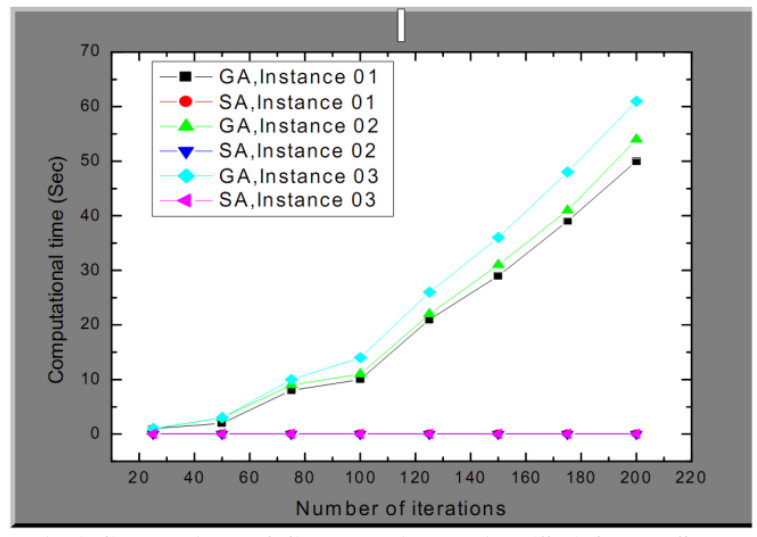

Fig:9 Comparison of Computational Time(Sec) for VBS by proposed algorithms(Instance 01,02 and 03 )

Comparison of Make span \& total transportation cost for constant batch size (CBS) by the proposed evolutionary algorithms for instance 01,02 and 03 is depicted in Fig.4 and Fig.5. The plot shown in Fig .4 and Fig.5 is styled for $6 \mathrm{M}-6 \mathrm{~B}-6 \mathrm{O}, 7 \mathrm{M}-7 \mathrm{~B}-7 \mathrm{O}$ as well as for 9M-9B-9O. It is observed that, there are moderate variations in results of MAKSP and TTC against number of iterations shown in the plot for GA and SA for instance 01,02 and 03 which means MAKSP and TTC is superior at the initial iteration and carry on with fluctuations in mid iteration and reaches a minimum value.

Comparison of Make span and total transportation cost for variable batch size (VBS) by the proposed evolutionary algorithms for instance 01,02 and 03 is depicted in Fig.6 and Fig.7. The plot shown in Fig .6 and Fig. 7 is styled for $6 \mathrm{M}-6 \mathrm{~B}-6 \mathrm{O}, 7 \mathrm{M}-7 \mathrm{~B}-7 \mathrm{O}$, It is observed that, there are better variations in results of
MAKSP and TTC against number of iterations shown in the plot for GAfor instance 01, 02 03which means MAKSP and TTC is higher at the initial generation and continue with fluctuations in middle generation and reaches to a minimum valve. In the same plots, we observed that SA results are constant and does not responded for instance 01,03 and little variations for instance 02 as the number of iterations increased.

Comparison of computational time (sec) by the proposed evolutionary algorithm for instance 01, 02and 03 for constant batch size (CBS) and for variable batch size(VBS) are shown in Fig. 8 and Fig.9. It is observed that GA requires fraction of sec for computing given input to optimum solution but SA gives the results with zero time, because it is a single solution method which is well known as trajectory based heuristic whereas GA is populationbased-heuristic which has many solutions (chromosomes) in a mating pool which can be reproduced as new offspring's (new solutions). Actually GA is an effective algorithm in searching local optima when compared with SA. Further, C++ code is running in a special compiler called The $\mathrm{C} / \mathrm{C}++$ Development Toolkit (CDT). The CDT is a collection of Eclipse-based features that provides the capability to create, edit, navigate, build, and debug projects that use $\mathrm{C}++$ as a programming language.

\section{$\mathrm{X}$ CONCLUSION}

This paper contracts with the single row machine layout design with integrated scheduling in which the frequency of trips between machines, theclearance between the machines with loading and unloading distance from loading/unloading station to all machines and unit material handling cost(MHD) are estimated differently. The problem is framed as the QAP formulation of facility layout problem. This is owing to the point that in the QAPmodels the distance between the positions of slots is identified well in advance but it is order dependent for the instances considered in this paper.From the results we conclude that, single row layoutis optimized using GA are better than SA with constant MHDcost and frequency of trips between machines. The parameter like transportation cost with machine sequences is determined for single row layout by running the program for five test runsThe performanceof the proposed algorithm is tested over a number of problems selected from the literature andis compared to many other algorithms existing in the literature. The experimental results reveal thatthe proposed GeneticAlgorithm is effective and efficient for single row machine layout design. From the graph it is clear that for single row layout, the total transportation cost is higher at the initial generation and continue with fluctuations in middle generation and reaches to a minimum valve.Finally, GA gives the best solution when compared with SA because GA is population 
based stochastic process which has plenty of solutions in a mating pool of an iteration whereas SA is trajectory based heuristic which has single solution to be modify in each iteration.

\section{REFERENCES}

[1]. William W.Luggen (1991) flexible manufacturing cells and systems. (Prentice-hall, Inc: A division of Simon \&schustesEnglewood cliffsnewjersy, 07632 ISBN 0-13321738-8).

[2]. Tompkins ja, white ja, bozerya, janchocoJmn (2003) facilities plannin. $\left(3^{\text {rd }}\right.$ edn: wiley, New York).

[3]. Apple Jm (1977) plant layout and material handling. ( $3^{\text {rd }}$ edn. The Ronald press co, New York).

[4]. MIKELL.P.GROOVER (1992) Automation, Production systems and computer-integrated manufacturing. (PrenticeHall Inc: ISBN-0-87692-618-9).

[5]. Ruey-Mawchen and Shin-Tang Lo (2006).Using ant colony system to solve resource constrained project scheduling problems. Int-J.compsci\& network secu vol.6 No-11, November 2006.

[6] ShahramAriafar, Napsiah Ismail.,“ An improved algorithm for layout design in cellular manufacturing systems" International Journal of Manufacturing system 176 (2006) 237-262, 28 132_139doi:10.1016/j.jmsy.2010.06.003, 2010 The Society of Manufacturing Engineers. Published by Elsevier Ltd.

[7]. R.M. sateeshkumar, p.Ashokan, s.kumanan (2008) design of loop layout. Inflexible manufacturing system using nontraditional optimization technique.Int. J.Adv manufacturing technology (2008) 38:594-599.

[8] Jerald.J, Ashokan.p, Saravanan.R (2006) simultaneous scheduling of parts and AGV in an FMS environment using adaptive genetic algorithm. Int.J.AdvManufacturing technology (2006) 29:584-589.

[9]. Hongbo Liu, Ajith Abraham, CrinaGrosan, Ningning Li, a novel variable neighbourhood particle swarm optimization for multi-objective flexible job-shop scheduling problems.2nd International Conference on Digital Information Management(2007).ICDIM-07. Vol 1,138-145. 